\title{
geosciences
}

ISSN 2076-3263

www.mdpi.com/journal/geosciences

Technical Note

\section{Hydrophobization by Means of Nanotechnology on Greek Sandstones Used as Building Facades}

\author{
Maria Stefanidou $^{1, *}$, Katia Matziaris ${ }^{2}$ and Georgios Karagiannis ${ }^{3}$
}

1 Civil Engineering Department, Aristotle University of Thessaloniki, Thessaloniki 56124, Greece

2 Chemical Engineering Department, Aristotle University of Thessaloniki, Thessaloniki 56124, Greece; E-Mail: uzin@otenet.gr

3 "ORMYLIA" Foundation, Art Diagnosis Center, Sacred Convent of the Annunciation, Ormylia 63071, Chalkidiki, Greece; E-Mail: g.karagiannis@teemail.gr

* Author to whom correspondence should be addressed; E-Mail: stefan@civil.auth.gr;

Tel.: +003-023-1099-5635; Fax: +003-023-1099-5699.

Received: 2 November 2012; in revised form: 8 January 2013 / Accepted: 9 January 2013 /

Published: 18 January 2013

\begin{abstract}
Modern sustainable architecture indicates the use of local natural stones for building. Greek sandstones from Epirus (Demati, Greece, EN 12440) used as building facades meet aesthetic and have high mechanical properties, but the inevitable interaction between stone materials and natural or anthropogenic weathering factors controls the type, and extent of stone damages. In the present paper, samples of sandstone were treated with a conventional hydrophobic product and four solutions of the same product, enriched with nanosilica of different concentrations. The properties of the treated samples, such as porosity and pore size distribution, microstructure, static contact angle of a water droplet, and durability to deterioration cycles (freeze-thaw) were recorded and conclusions were drawn. The research indicates the increased hydrophobic properties in nanosilica solutions but also the optimum content in nanoparticles that provides hydrophobicity without altering the properties of the stone.
\end{abstract}

Keywords: sandstone; hydrophobicity; nanosilica 


\section{Introduction}

Sandstone is a sedimentary rock widely found in Greek territory that has contributed to the cultural and architectural heritage in Greece and is still significant due to texture, appearance, and high mechanical properties which are compromising with the minimal decorating facade style of modern design. Sandstone from Epirus (Demati, Greece) is a certified rock, according to European Natural stone-Denomination criteria (EN 12440:2008) [1] as a compact green fossiliferous limy type (Table 1) sandstone with low porosity and high strength type (Table 2). All the described properties fully justify the capability of Demati sandstone for building applications.

Table 1. Composition of Demati sandstone.

\begin{tabular}{cccc}
\hline Mineralogical composition & $\mathbf{w} / \mathbf{w} \%$ & Chemical analysis & $\mathbf{w} / \mathbf{w} \%$ \\
\hline Calcite & 14.0 & $\mathrm{CaO}$ & 22.00 \\
Dolomite & 1.00 & $\mathrm{MgO}$ & 2.60 \\
Quartz & 56.00 & $\mathrm{SiO}_{2}$ & 45.20 \\
Micas & $<1$ & $\mathrm{Fe}_{2} \mathrm{O}_{3}$ & $<1$ \\
Chlorite & - & $\mathrm{AI}_{2} \mathrm{O}_{3}$ & 5.65 \\
Feldspars & 28 & $\mathrm{~K}_{2} \mathrm{O}$ & 25.30 \\
Epidote & - & $\mathrm{Na}_{2} \mathrm{O}$ & 0.01 \\
Chromite & - & $\mathrm{MnO}$ & $<0.01$ \\
\hline
\end{tabular}

Table 2. Physico-mechanical properties of Demati sandstone.

\begin{tabular}{ccc}
\hline Physicomechanical Properties & Unit & Value \\
\hline Bulk density & $\mathrm{kg} / \mathrm{m}^{3}$ (DIN 52102) & 2.825 \\
Open porosity coefficient & $\%$ vol (DIN 52102 & 0.54 \\
Water absorption coefficient & $\mathrm{w} / \mathrm{w} \%$ (DIN 52103) & 0.19 \\
Dynamic modulus of elasticity & $\mathrm{GPa}$ (DIN 1048 Teil 5) & 35 \\
Compressive Strength & $\mathrm{MPa}$ (DIN 52105) & 139 \\
Flexural strength & $\mathrm{MPa}$ (DIN 52112) & 10 \\
Compressive Strength after frost/defrost cycles & $\mathrm{MPa}$ (DIN 52104 \& 52105) & 103 \\
Abrasion resistance & $\mathrm{mm}$ (DIN 52108) & 2.20 \\
Impact Resistance & $\mathrm{cm}$ (UNI-U 32.07.248.0) & 59 \\
\hline
\end{tabular}

However, long-term interaction of stone with the environment causes a progressive decay of the natural consolidant, which is predominantly lime, and causes deterioration starting from the surface. Especially in the presence of water, as in humidity or rain, in combination with large temperature fluctuations and traffic emission create a very hostile environment for the building materials [2].

Furthermore, prolonged exposure to natural elements, man-made atmospheric pollution and temperature variations cause degradation [3] and may provide field for colonization by biological organisms [4]. Temperature changes, either gradual or sudden, cause stresses due to differential thermal expansion [5], and consequently cracking.

The chemical and physical properties of materials are important as they determine the result of the interactions with gases, particles, and solutions. Thus, solubility, corrosion resistance, weathering resistance, etc. are chemical properties strongly related to density, porosity, hardness, and other physical 
properties, but also to environmental factors [6]. The evaluation of weathering damages is based on lithological mapping, and mapping of weathering forms. Weathering forms represent the visible results of weathering processes, which are initiated and controlled by interacting weathering facts [7].

Sedimentary rocks, like sandstones, are usually considered as more susceptible to water deterioration as they are commonly soluble [8]. Numerous hydrophobic treatments to sandstones showed effective reductions in stone's water uptake in different extents depending onto the material and the action mechanism [9], e.g., oils, waxes, acrylic-, phenolic-, epoxy- and PU-resins, have been tested by researchers. Amongst the different tests performed in order to evaluate the effectiveness of the water repellents, the most representative assessment methods were selected [10], i.e., those which afforded the fastest and most reliable performance evaluation: color determination, water-stone contact angle, and water-vapor permeability.

Hydrophobic impregnation into a stone makes the mineral surface water-repellent, results in less water absorption, and consequently, less deleterious dissolved substances, therefore it means the protection of building materials [11].

Conclusions are that the most effective method is hydrophobic impregnation with silicone resin networks [12-15] because they provide impermeability to liquid water, permeability to water vapor, oil repellence, absence of color, chemical inertness, and environmental stability and energy saving [16].

Furthermore, surface energy and the three-dimensional surface microgeometry control the wetability of the solid surfaces with water. The more hydrophobic a surface is, the lower the surface energy and, therefore, the more water repellent it is. However, surface energy is an intrinsic property to each material, so lowering the surface energy is, by itself, not sufficient to produce an ultra water-repellency [17].

Generally it is recommended to modify the appropriate surface texture of surface geometry to imitate nature's "lotus effect" by means of nanoparticles in order to increase water-repellency [18].

Freeze-thaw cycles are an important environmental stress for external stone facades. Water expands when it freezes and can therefore enlarge cracks. Dew and/or frost are nightly occurrences in many climates. The covering temperature falls below the ambient air temperatures on clear nights due to the radiative cooling effect. If the relative humidity is high, dew or frost is formed. Water vapor is absorbed by stone materials. Changes in humidity lead to changes in the equilibrium of water content.

Broadly, water condensation in/or under any type of polymeric films occurs when the local vapor pressure is higher than that corresponding to the local dew point vapor pressure, which is conducive to adhesion reduction and even to complete delamination [18].

The present study investigates the water protection efficacy of Demati sandstone through the use of hybrid surface coatings, derived by combination of a commercial solvent-based mixture of silicone water repellent, in several concentrations, with amorphous $\mathrm{SiO}_{2}$ nanoparticles.

\section{Experimental Materials}

All the sandstone samples were cut by laser machinery into prismatic blocks with dimensions of $2 \times 2 \times 5 \mathrm{~cm}$. Prior to the impregnation, all samples have been washed with pressured water-fog and thereafter with acetone for two hours. Finally, all the samples have been stored in desiccators set to $50{ }^{\circ} \mathrm{C}$ and $50 \% \mathrm{RH}$, for $24 \mathrm{~h}$ to achieve residual solvent removal. The impregnation was carried out by immersion and saturation of the stone samples with the polymer solution for five minutes. 


\subsection{Protective Coatings for Impregnation}

Analytically, the coatings that have been prepared in the present study come from a commercial solvent-based mixture of silane, siloxane, and fluoropolymer $(<\mathrm{C} 8)$ under the trade name SILRES BS 38 [18], provided by WACKER Chemie A.G. (Burghausen, Germany) in a proportion of $20 \% \mathrm{w} / \mathrm{w}$ diluted in organic naphtha SHELSOL D 40 [18].

The above-mentioned polymeric solution was divided into five parts and each one was enriched with amorphous hydrophobic silicon dioxide nanoparticles under the trade name of H.D.K. H18 [17] (BET surface 170-230 $\mathrm{m}^{2} / \mathrm{g}$ ). The gradually increasing concentrations of the nanoparticles in the polymer mixture were, per weight: $0 \%, 1 \%, 1.5 \%, 2 \%$ and $2.5 \% \mathrm{w} / \mathrm{w}$.

After the nanoparticles' addition, all the solutions were subjected to Ultrasonic bath for one hour (Branson 2510), in order to ensure the best dispersion. The following table shows the nomenclature and the solution-uptake after the immersion into the solutions (Table 3). The sample D2 was treated with the polymeric solution without nanosilica enrichment.

Sandstone was immersed in the solutions and left for fine minutes in ambient $20{ }^{\circ} \mathrm{C}$. Then samples were left on a bench at the same conditions for seven days, before any test was performed, in order to drain off the liquid that remained on the surfaces after the samples' saturation. The values of the solution uptake present fluctuations, but the samples coded D4 with 1.5\% nanoparticles present the highest amount of solution absorption.

Table 3. Nomenclature and properties of the treated samples.

\begin{tabular}{ccc}
\hline Sample & $\mathrm{SiO}_{\mathbf{2}}(\mathbf{w} / \mathbf{w} \%)$ & Solution Uptake (\%) \\
\hline D1 & Untreated & - \\
D2 & 0 & 0.114 \\
D3 & 1 & 0.115 \\
D4 & 1.5 & 0.153 \\
D5 & 2 & 0.080 \\
D6 & 2.5 & 0.106 \\
\hline
\end{tabular}

\subsection{Techniques and Methods of Analysis}

The experiments performed concerned the determination of open porosity, water absorption, and samples' density according to RILEM CPC11.3 [19]. Furthermore, the porosity and the pore size distribution was measured using mercury porosimetry (Quantachrome Macro, Boynton Beach, FL, USA). The stereoscopic observation was conducted by LEICA WILD M10 (Zeiss-Abro, Zaandam, The Netherlands) and Scanning Electron Microscopy (SEM) using a JEOL 840A JSM (JEOL, Tokyo, Japan).

The water contact angle measurements were conducted using distilled water and a Kruss G10 (Hamburg, Germany) goniometer-Optical Surface Tension/Contact Angle meter instrument. Additionally, the durability tests were performed after freeze-thaw exposures tests to temperatures ranging from $-18{ }^{\circ} \mathrm{C}$ to $20{ }^{\circ} \mathrm{C}$, in two ways: (a) by salt solution and (b) by air in a climatic chamber (Angelantoni GTS600, Massa Martana, Italy). Finally the evaluation of the thin film's penetration depth into the mineral surface was made using acoustic microscopy [20,21]. 


\section{Results and Discussion}

\subsection{Microscopic Observation}

The stereoscopic examination of Demati samples through a lens $(\times 10)$ displays a typical sandstone texture, which is predominated by clay minerals in a fine grained matrix with medium sugar-like calcitic crystals, well bonded, with no high percentage of voids.

The stereoscopic optical examination was especially revealing of a gradual differentiation of the glass-like texture for the untreated sandstone sample (Figure 1a) to the whitish, crusted, "fluffy" substratum (Figure 1f). This texture is fully harmonized by the higher nanosilica content from 0 to $2.5 \mathrm{w} / \mathrm{w} \%$. Initially the color of the sandstone was a green/gray color but, due to the nanoparticles increase, it turned to a light grey/green with whitish layer/crust on the mineral surface. The higher the content of nanoparticles, the more marked was the phenomenon of the white crust. The layer was uniformly applied and no density differences were recorded (Figure $1 \mathrm{~b}-\mathrm{f}$ ).

SEM analysis performed on the samples indicates small differences in the structure of the untreated sample and the sample treated with the neat hydrophobic material. Large angular crystals of feldspars prevail in the structure of the sandstone while the coating of hydrophobic material uniformly covers the surfaces, making the crystals look smaller and restricting the pores between them (Figure 2).

Figure 1. (a) D1 untreated; (b) D2 polymeric no nanosilica; (c) D3 $1 \mathrm{w} / \mathrm{w} \%$ nanosilica; (d) D4 $1.5 \mathrm{w} / \mathrm{w} \%$ nanosilica; (e) D5 $2 \mathrm{w} / \mathrm{w} \%$ nanosilica; (f) D6 $2.5 \mathrm{w} / \mathrm{w} \%$ nanosilica.

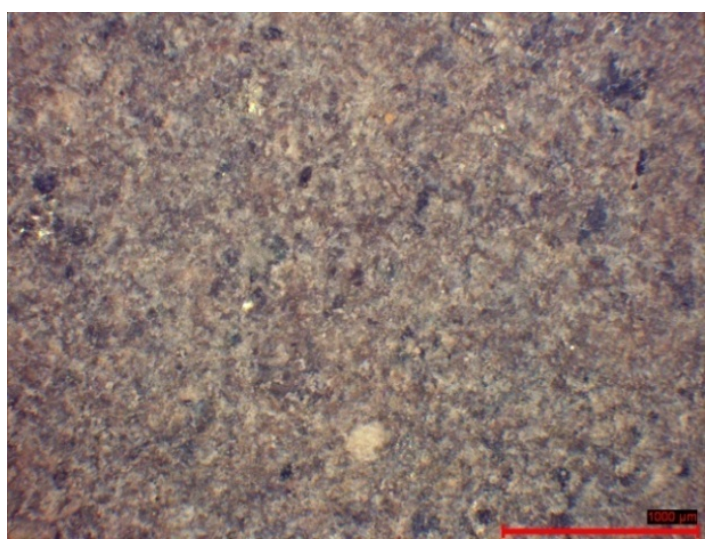

(a)

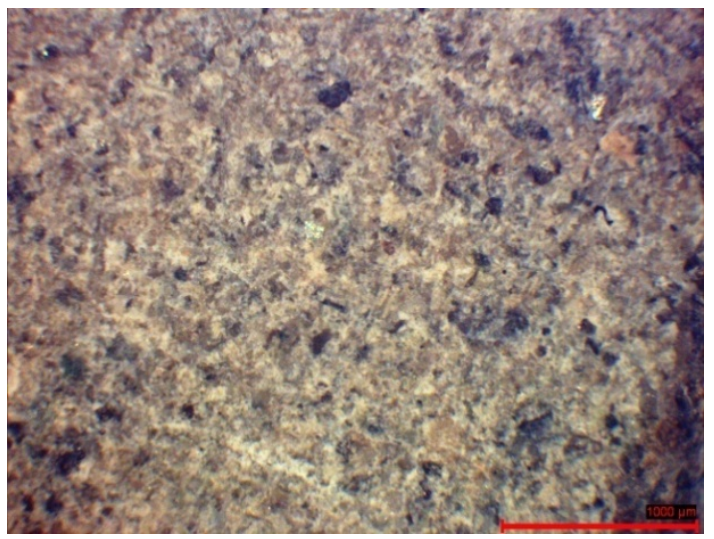

(c)

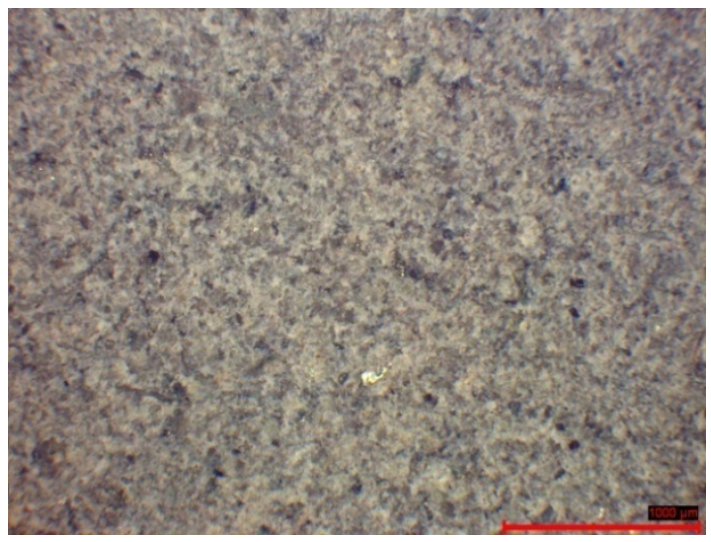

(b)

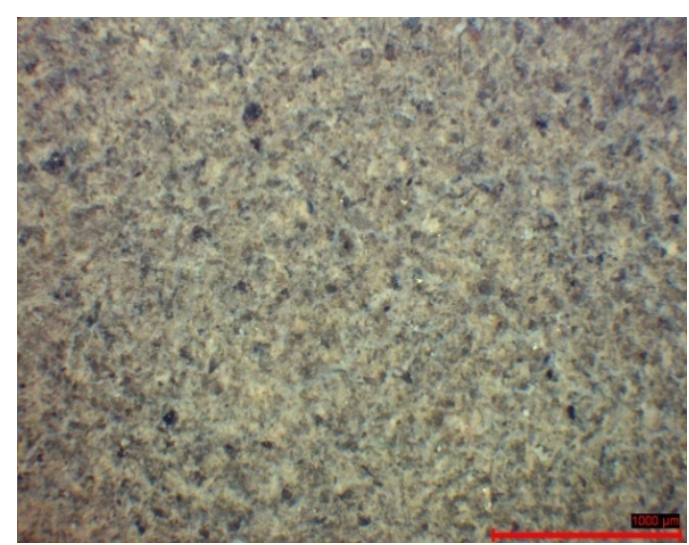

(d) 
Figure 1. Cont.

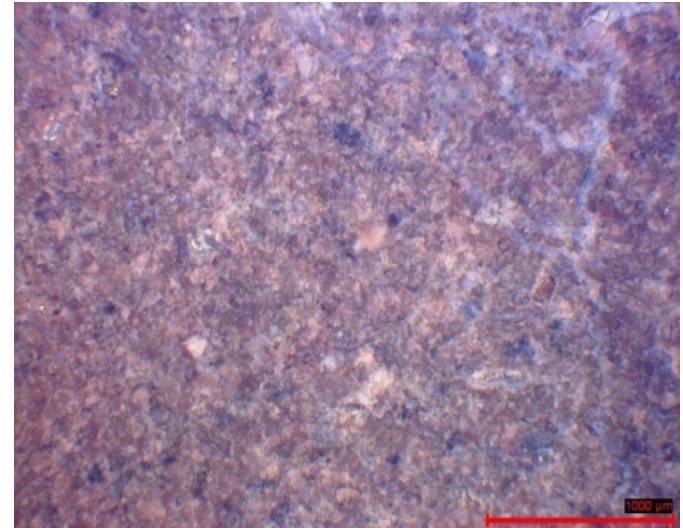

(e)

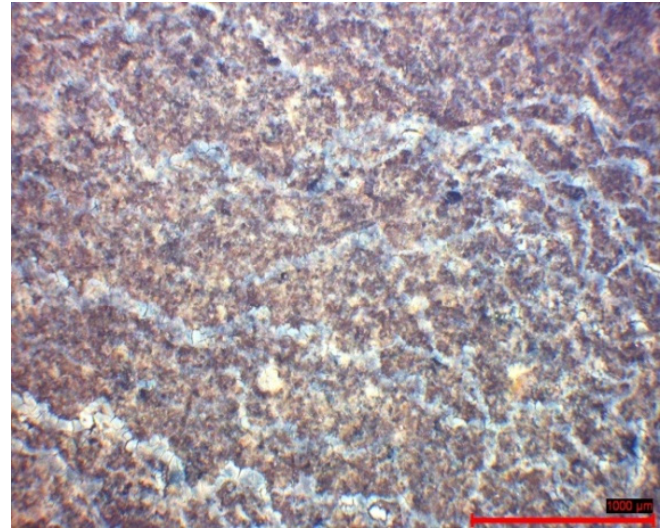

(f)

Figure 2. (a) Untreated sample and (b) sample treated with hydrophobic layer.

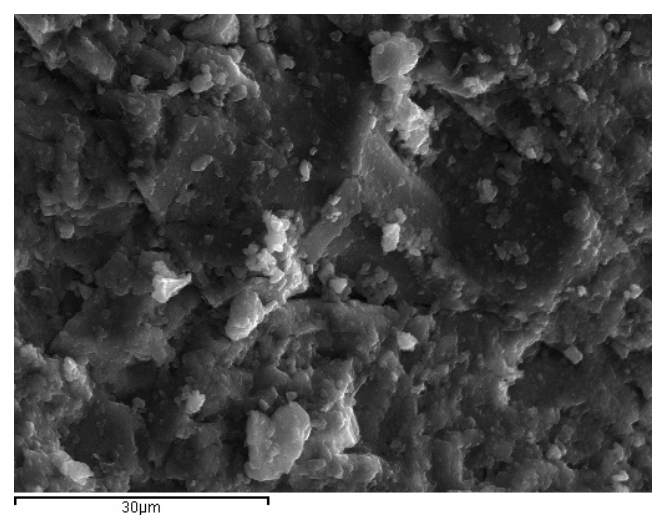

(a)

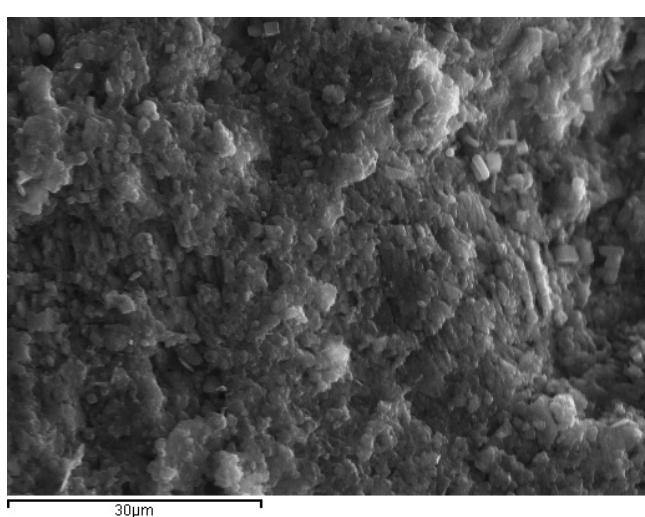

(b)

In samples treated with coatings containing nanosilica, a layer was observed, causing the smoothening of the surface because the natural crystallic relief is covered by the thin hybrid membrane. In the case of the D4 sample (Figure 3a), this layer was almost uniform and continuous, fully covering the mineral inorganic substratum. In the case of the D6 sample, the higher the nanosilica consistency the more the possibilities of agglomeration, and therefore intense agglomeration "island" and cracks/discontinue-ties in some places of the layer were observed (Figure $3 b$ ).

Figure 3. (a) Surface of D4 sample and (b) surface of D6 sample under SEM.

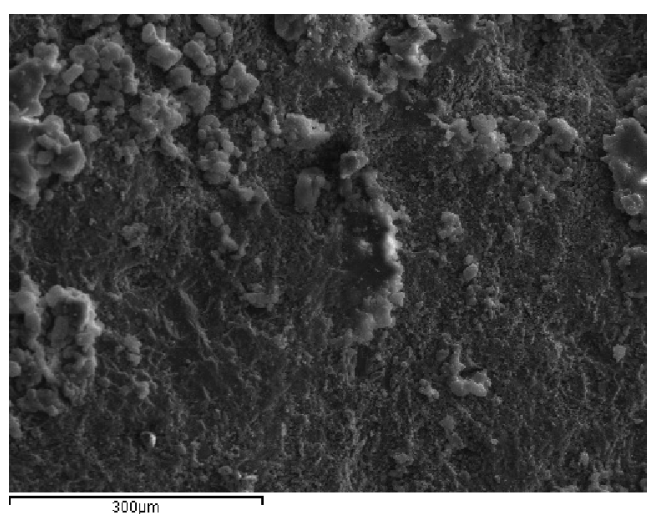

(a)

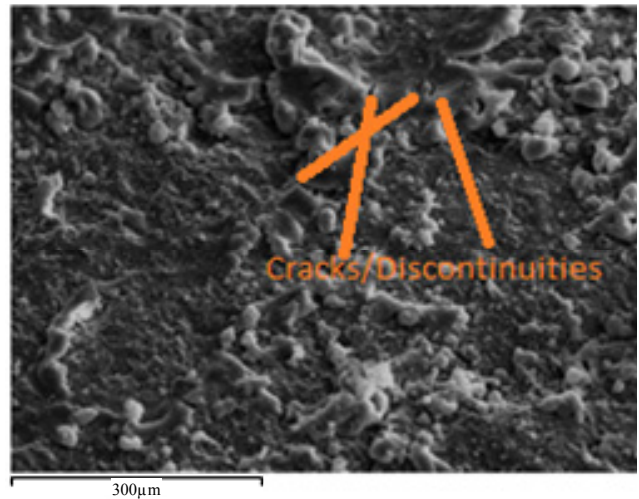

(b) 


\subsection{Water Absorption}

The water absorption test was performed under vacuum, according to RILEM CPC11.3 and Table 4 contains the results while Figure 4 gives the relation between the absorption and the porosity. The method of liquid (usually distilled water) absorption in order to measure open porosity is quick, cost effective, and reliable, since it is easily repeatable [22]. During the procedure of this method, the pore shape does not present any alterations and it is considered trustful when permeability estimation is required. It is based on the concept that the sample weight is due to its absolute mass. Firstly the samples should be dried, and air present should be removed through suction. By filling the pores with a liquid medium of known density at normal temperature, open porosity can be calculated from the weight change. The assumption of this method is that only connected pores open to the surface of the sample can be measured, and only pores (not solid parts) are filled with the liquid. Samples should be under vacuum in order to extract air and allow liquid to penetrate deeper or into smaller pores.

Table 4. Water absorption test results.

\begin{tabular}{ccccc}
\hline Samples & Absorption (\%) & Specific gravity $\left(\mathbf{g} / \mathbf{c m}^{\mathbf{3}}\right)$ & Open porosity $\mathbf{( \% )}$ & Porosity Index \\
\hline D1 & 1.072 & 2.636 & 2.827 & - \\
D2 & 0.469 & 2.692 & 1.198 & -0.576 \\
D3 & 0.365 & 2.541 & 0.913 & -0.677 \\
D4 & 0.195 & 2.497 & 0.488 & -0.827 \\
D5 & 0.295 & 2.592 & 0.764 & -0.730 \\
D6 & 0.289 & 2.542 & 0.734 & -0.740 \\
\hline
\end{tabular}

Figure4. Absorption and porosity data.

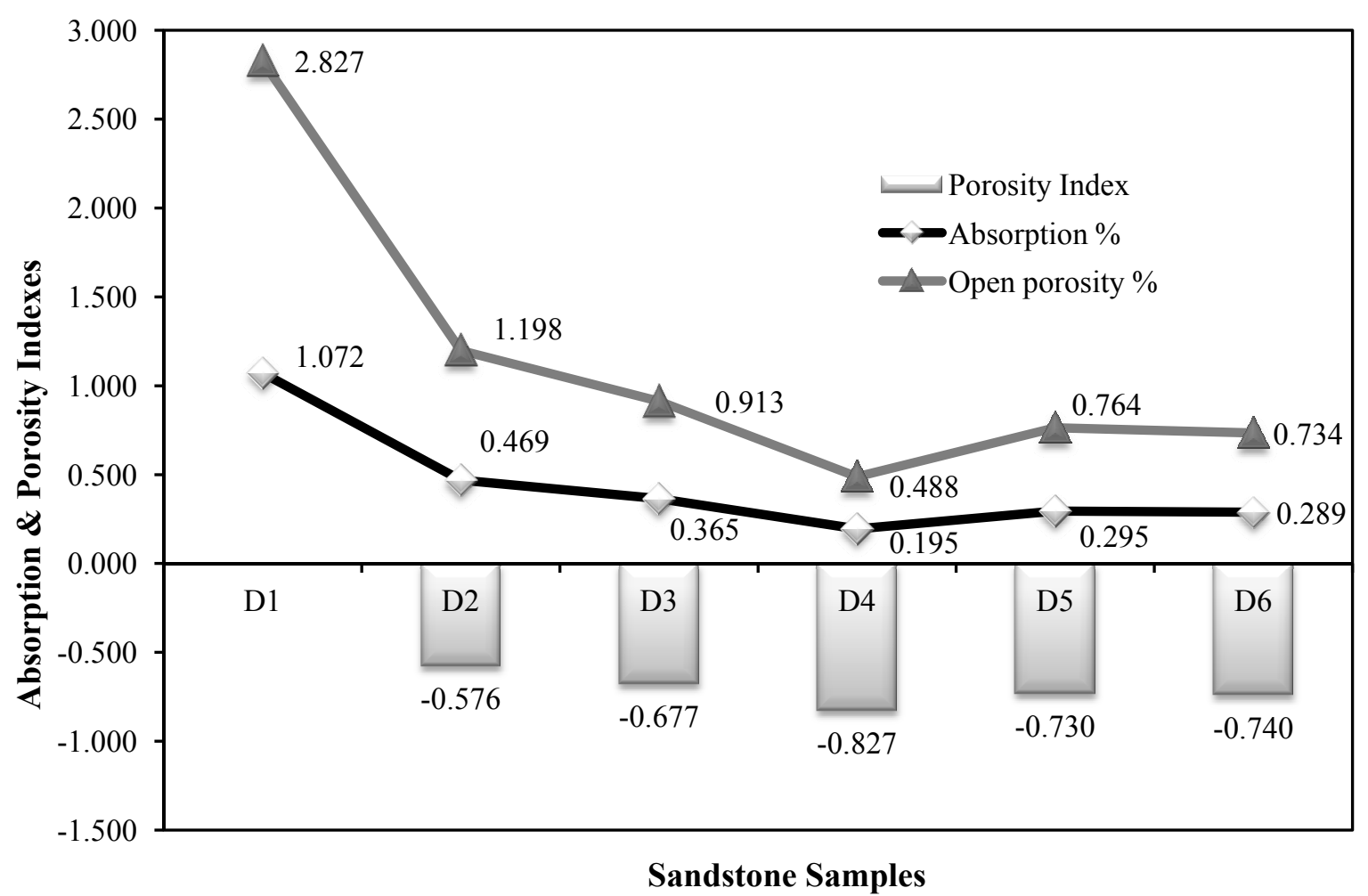


From the results we derived that the addition of nanoparticles reduced the water absorption but the lower porosity and water absorption was successful in sample D4 with $1.5 \%$ nanoparticles.

\subsection{Mercury Porosimetry}

Mercury Intrusion Porosimetry according to ASTM D 4404-84 [23] provides a wide range of pore sizes and properties such as open porosity, mean pore diameter, and bulk density. This technique is the most common one used by researchers in different building materials [24] and has been proved sensitive for comparisons. The pore-size distribution is determined from the volume of mercury intruded at each pressure increment, while the total porosity is based on the total intruded volume. In this case, the untreated Demati sandstone presents a range of pore sizes from $10 \mu \mathrm{m}$ to $200 \mu \mathrm{m}$. All treated samples do not present large pores $(>200 \mu \mathrm{m})$. Small pores in the area of of $<20 \mu \mathrm{m}$, samples treated with solution containing $2 \%$ nanoparticles (D5) present large amount of pores, while D2 and D4 samples have similar distribution to the untreated stone (Figure 5).

Figure 5. Pore size distribution by mercury porosimetry.

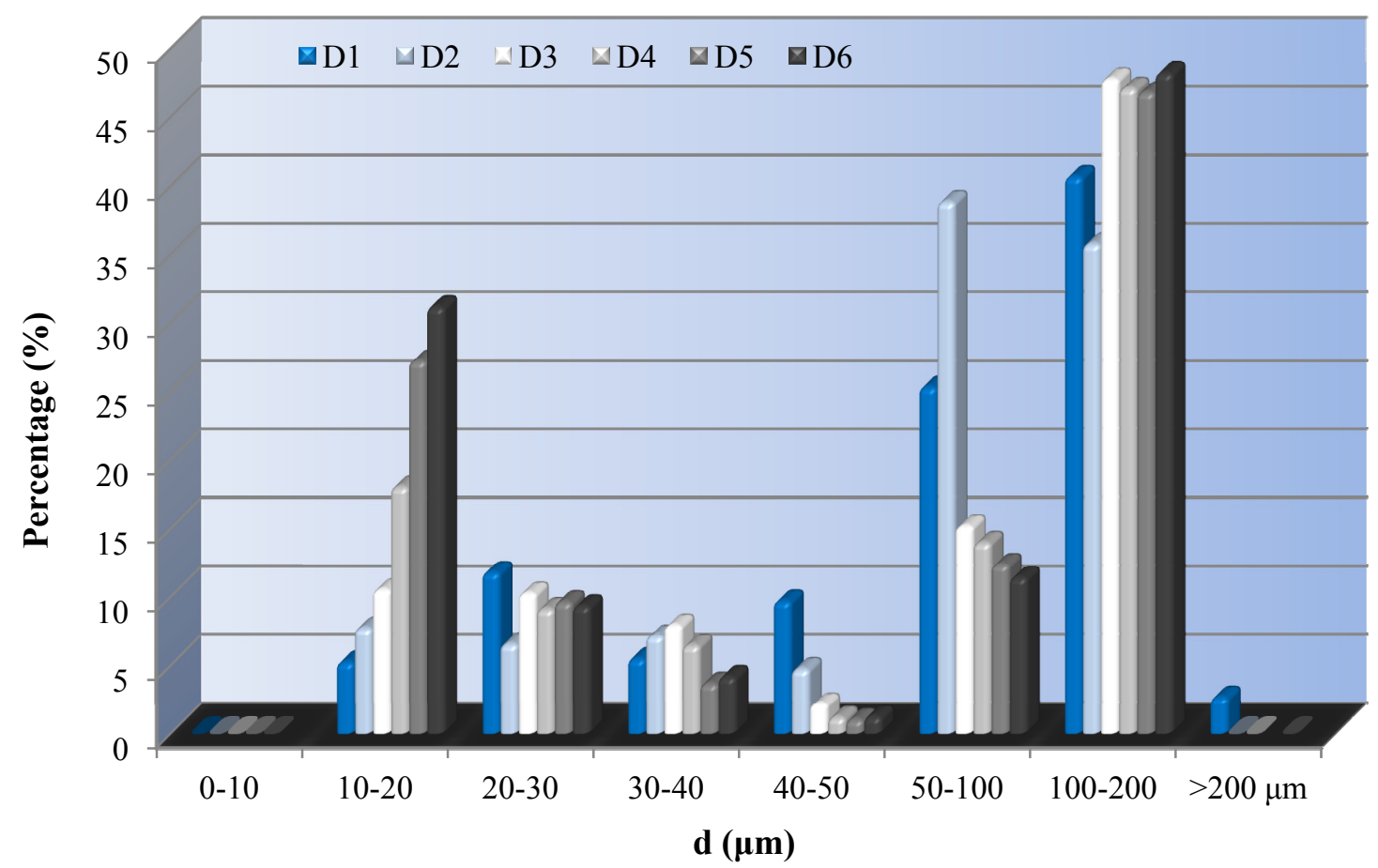

\subsection{Water Contact Angle}

When a porous building material, such as stone, comes into contact with (liquid) water, water is sucked into the pores of the material by capillary forces. The capillary forces are determined by: the surface tension of the liquid, the contact angle between the liquid and the pore walls, and the radius of the pores. Narrow pores attract moisture more strongly (higher) than wide pores. A viscous liquid is less quickly attracted, than a thin liquid substance.

A small contact angle indicates molecular attraction between the liquid and the substrate. A liquid drop spreads over a flat surface; the meniscus in a capillary lies above the level of the surrounding 
liquid and is hollow towards the "dry" side. In the absence of such attraction between a solid substance and a liquid, a drop remains on the surface in the form of a sphere. Water contact angle measurements were conducted using distilled water with a Kruss G10 Goniometer-Optical Surface Tension/Contact Angle meter instrument. Three droplets of water were delivered to different points on each specimen and from a height sufficiently close to the substrate, so that the needle remained in contact with the water droplet. Then, the delivery needle was withdrawn with minimal perturbation to the drop. The volume of each droplet was $5 \mu \mathrm{L}$. Contact angle was calculated by the static drop method. Wettability is depicted in macroscopical terms of contact angle, that is related to the interfacial tensions, or surface energies, through Young's equation in the ideal situation of a perfectly smooth and homogeneous surface that corresponds to the unique equilibrium position of the solid-liquid-air contact line (the triple line). Samples' surfaces have been divided into $0.5 \mathrm{~cm}^{2}$ grids, and 10 measurements have been reported and then statistically used the average price with standard deviation $\mathrm{SD}= \pm 0.01$.

The static water contact angle (SCA) on the untreated specimens was around $50^{\circ}$. Hydrophobization by commercial impregnants with unmodified siloxane composition increases the SCA up to $123^{\circ}$. The addition of silica nanoparticles further increases the hydrophobicity of the surface, and for particle concentrations of $1.5 \mathrm{w} / \mathrm{w} \%$ it renders the surface super-hydrophobic (Table 5).

The test was performed in the samples and the results are shown in Figures 6 and 7 confirming the increased hydrophobicity developed in treated samples. The sample D4 presented super-hydrophobic behavior with contact angle $143.73^{\circ}$.

Table 5. Water contact angle measurements.

\begin{tabular}{cccc}
\hline Sample & Static Contact Angle $\left({ }^{\circ} \mathrm{C}\right)$ & $\mathbf{E}_{\mathbf{c a}}=\mathbf{C A} / \mathbf{9 0}^{\circ}$ & Threshold \\
\hline D1 & 51.43 & 0.571 & 1.00 \\
D2 & 123.13 & 1.500 & 2.78 \\
D3 & 140.20 & 1.558 & 2.73 \\
D4 & 143.73 & 1.597 & 2.79 \\
D5 & 140.03 & 1.556 & 2.72 \\
D6 & 140.97 & 1.566 & 2.74 \\
\hline
\end{tabular}

Figure 6. Static contact angle (SCA) of a water drop of untreated (a) sample D1; (b) sample D2; (c) sample D3; (d) sample D4; (e) sample D5 and (f) sample D6.

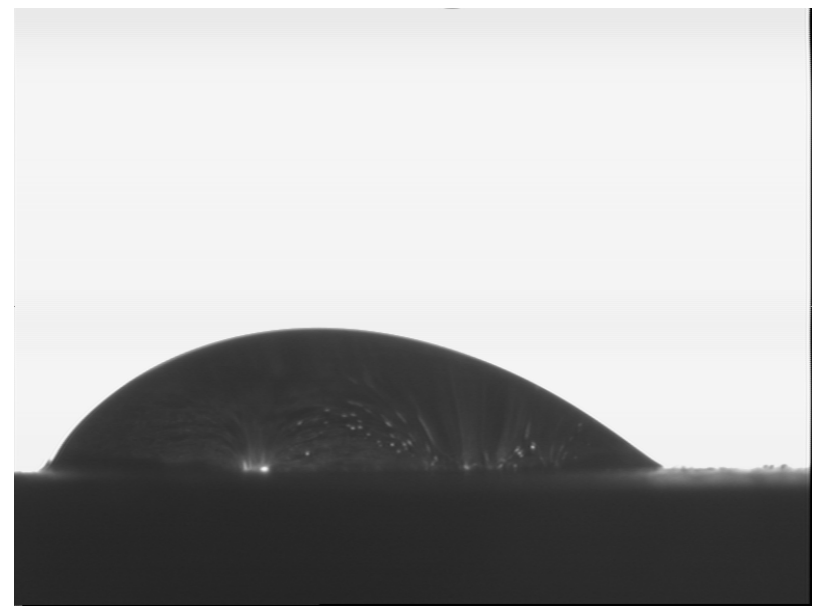

(a)

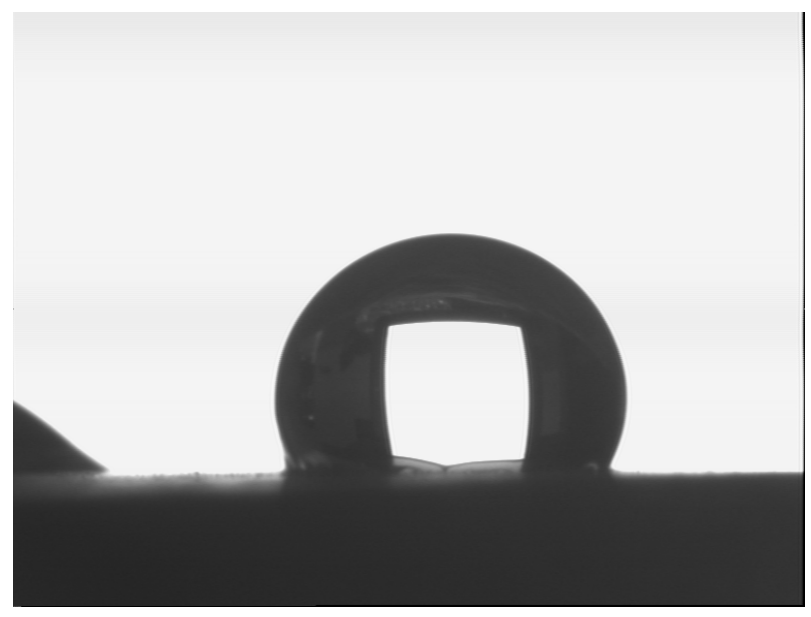

(b) 
Figure 6. Cont.

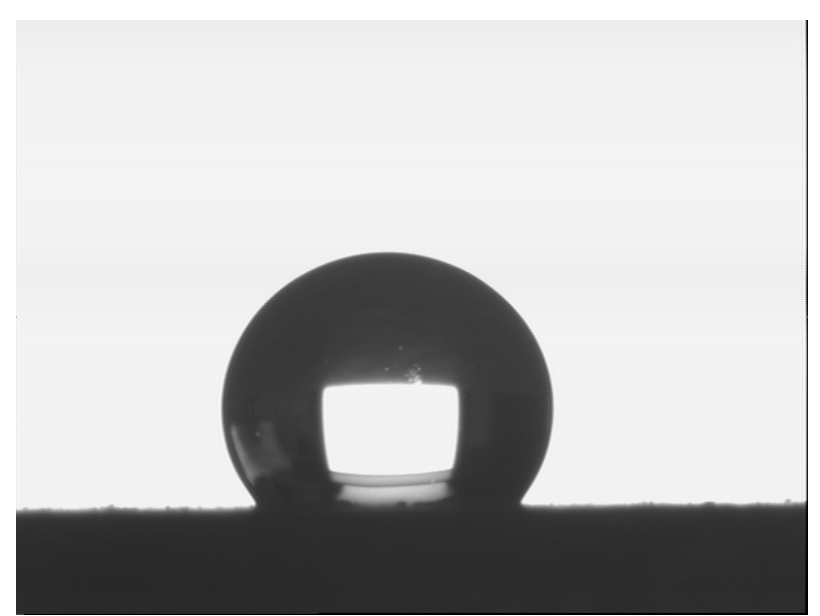

(c)

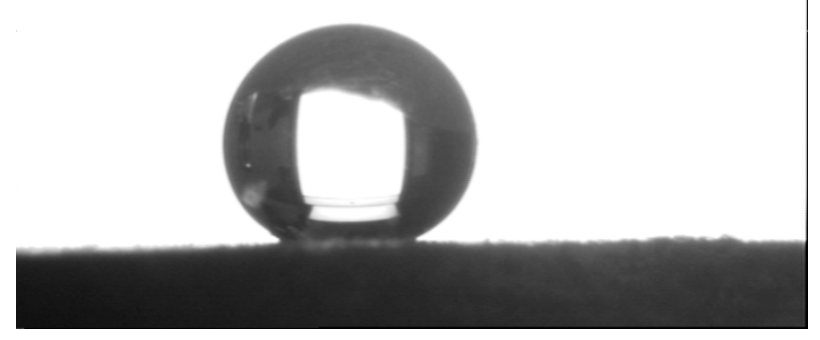

(e)

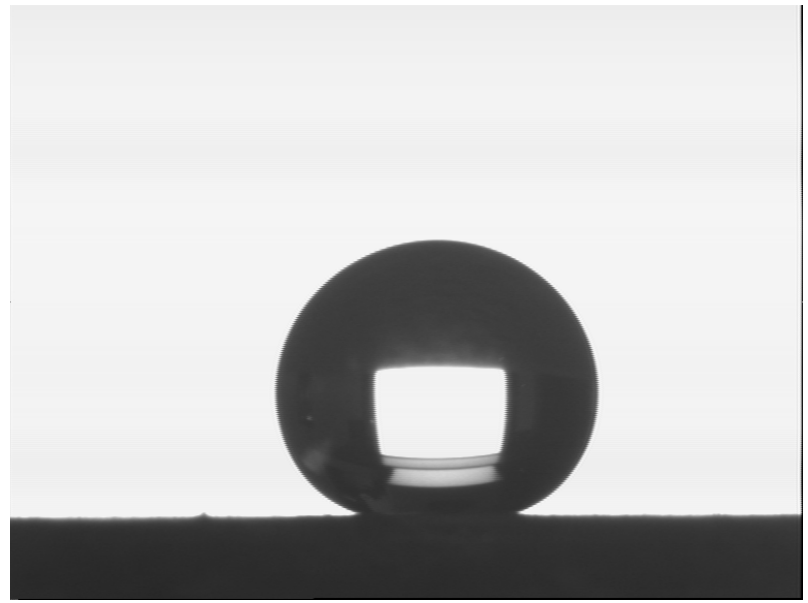

(d)

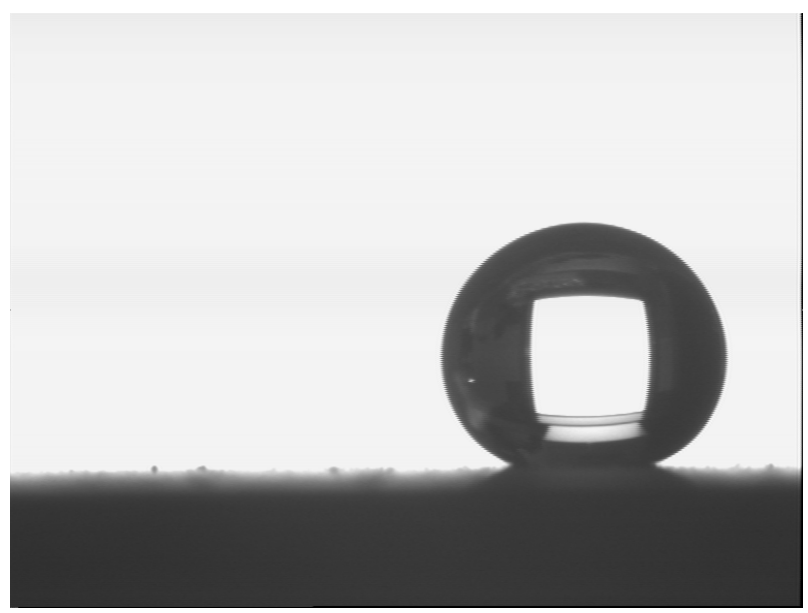

(f)

Figure 7. Static contact angle index $\mathrm{E}_{\mathrm{ca}}$ and threshold.

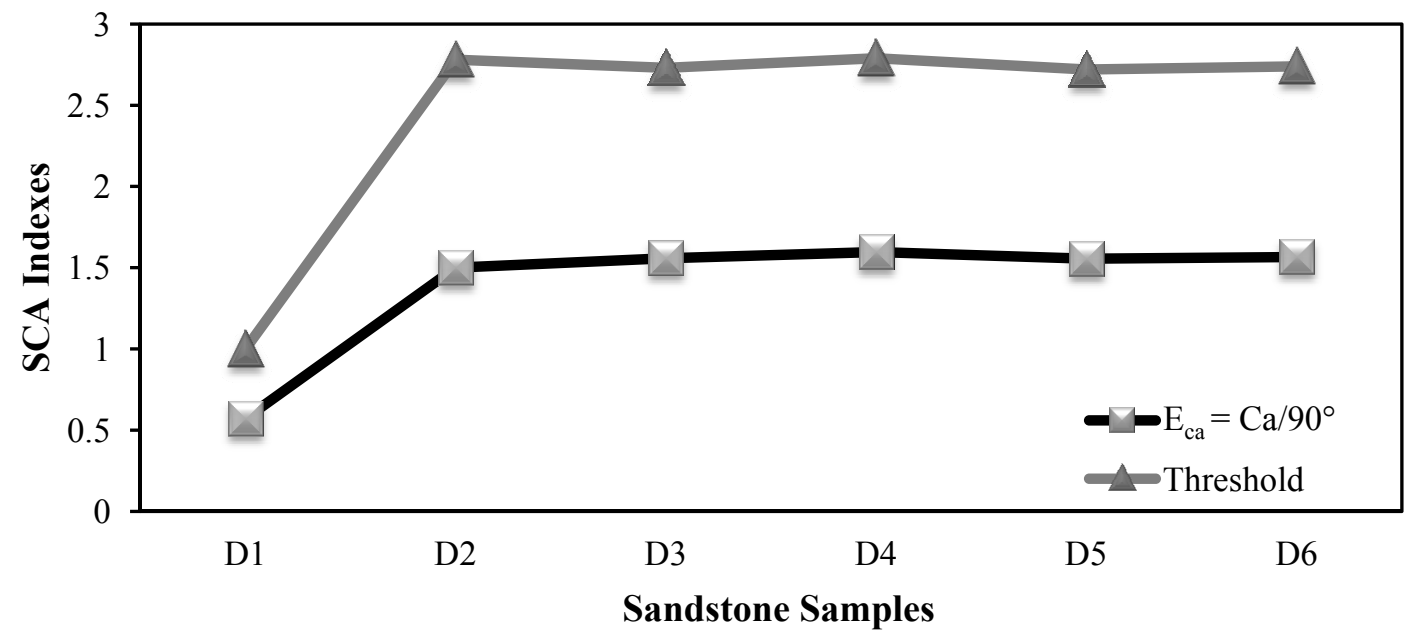

\subsection{Freeze-Thaw Test Results}

Additionally to air freeze-thaw cycle tests, samples have been subjected to salt fog cycle tests. Because salt fog reaction is essential to weathering mechanisms, such as salt crystallization-deposition 
onto rock surfaces, or salt solution penetration into rock-pores causing expansion of existing voids in the rock geometry or secondary minerals genesis [25,26]. Thus two series of samples were weighted and put in a climatic chamber in order to subject them to freeze-thaw tests. One was left in air and the other was immersed in a solution of $10 \% \mathrm{NaCl}$. In total 260 cycles were performed according to EN12371:2001 [27] from $-18{ }^{\circ} \mathrm{C}$ to $20^{\circ} \mathrm{C}$. After the end of the program all samples were visually inspected and the loose material of each sample was weighted again. The weight loss data is given in Table 6. All samples lost approximately $0.30-0.45 \mathrm{w} / \mathrm{w} \%$ of their mass, while were exposed in freeze-thaw cycles in air (Figure 8). Notable, is that minimum loss was observed in samples D5 and D6. The loss of mass was more intense in samples exposed to the saline solution of salt fog. There was an observed loss of approximately $0.60-0.75 \mathrm{w} / \mathrm{w} \%$ of original weight and samples D5 and D6 were again the most durable.

Table 6. Weight loss after the freeze-thaw cycle testing per $\mathrm{w} / \mathrm{w} \%$.

\begin{tabular}{ccc}
\hline Sample & Weight loss on air (\%) & Weight loss in saline solution $(\%)$ \\
\hline D1 & 0.45 & 0.75 \\
D2 & 0.41 & 0.65 \\
D3 & 0.40 & 0.70 \\
D4 & 0.40 & 0.62 \\
D5 & 0.30 & 0.60 \\
D6 & 0.30 & 0.60 \\
\hline
\end{tabular}

Figure8. Freeze-thaw cycles weight loss comparison.

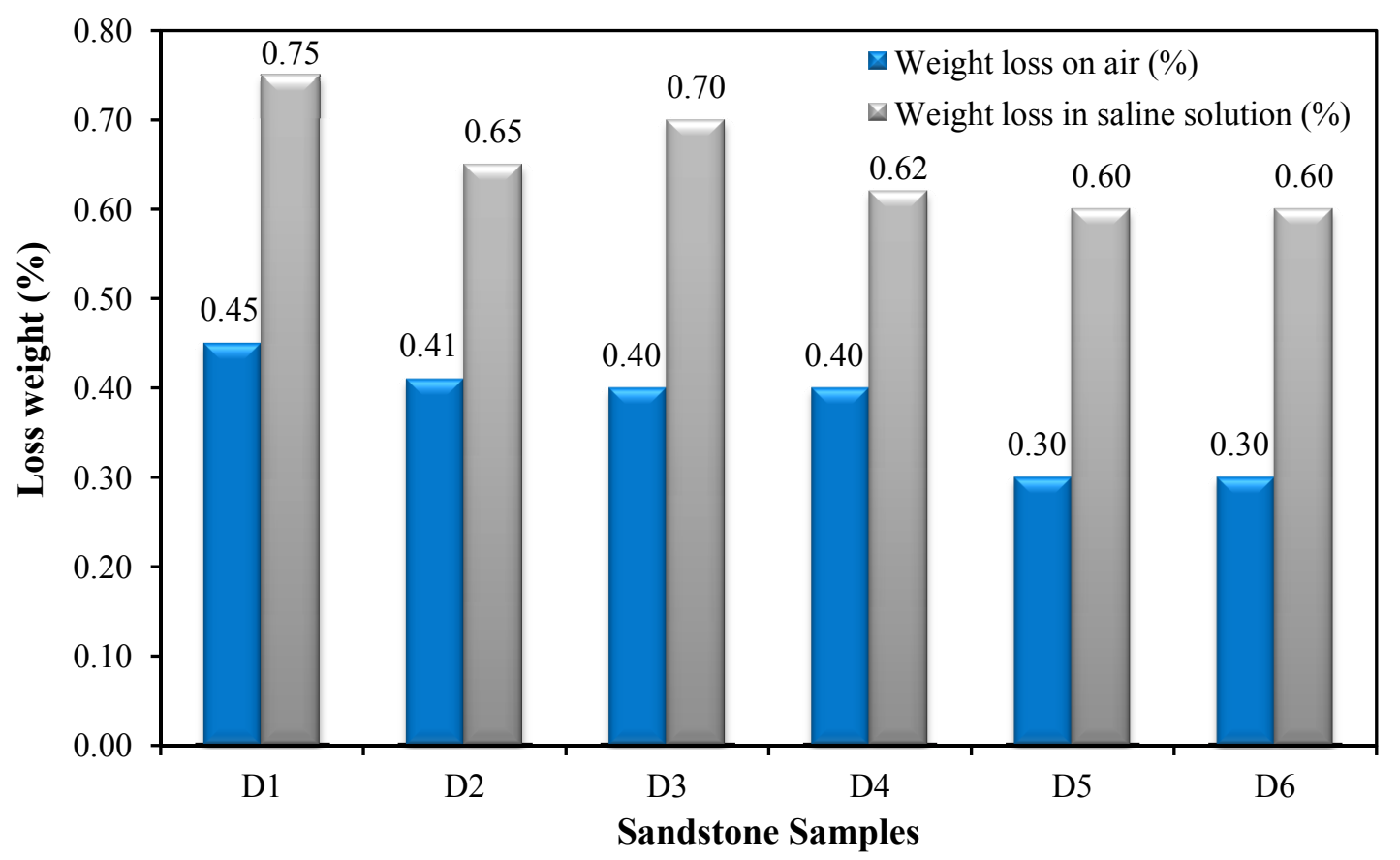

\subsection{Acoustic Microscopy}

The ultrasonic waves are emitted from the transducer into the coated thin film through the used coupling gel material. The ultrasound propagates from the transducer to the thin film and consecutively to the various layers of the sandstone. Echoes are generated by the various interfaces 
between the different kinds of materials. The echoes are received by the transducer at different time instances, which are proportional to the distance of the interfaces from the transducer[28-30]. The signal that contains the echoes consists the a-scan signal. From the Time of Flight (TOF) of two successive echoes, generated by the surface of the thin film (A) and the interface between the thin film and the sandstone material (B) (in Figure 9), the thickness can be calculated. This is a real time measurement, lasting a few seconds in the case that a set of measurements is acquired in a region of interest of the sandstone.

Figure 9. Pulse echo technique used for the thickness measurement of the thin film penetration. (a) Representation of the measurement; In (b) A stands for the echo of the thin film and B stands for the echo of the sandstone.

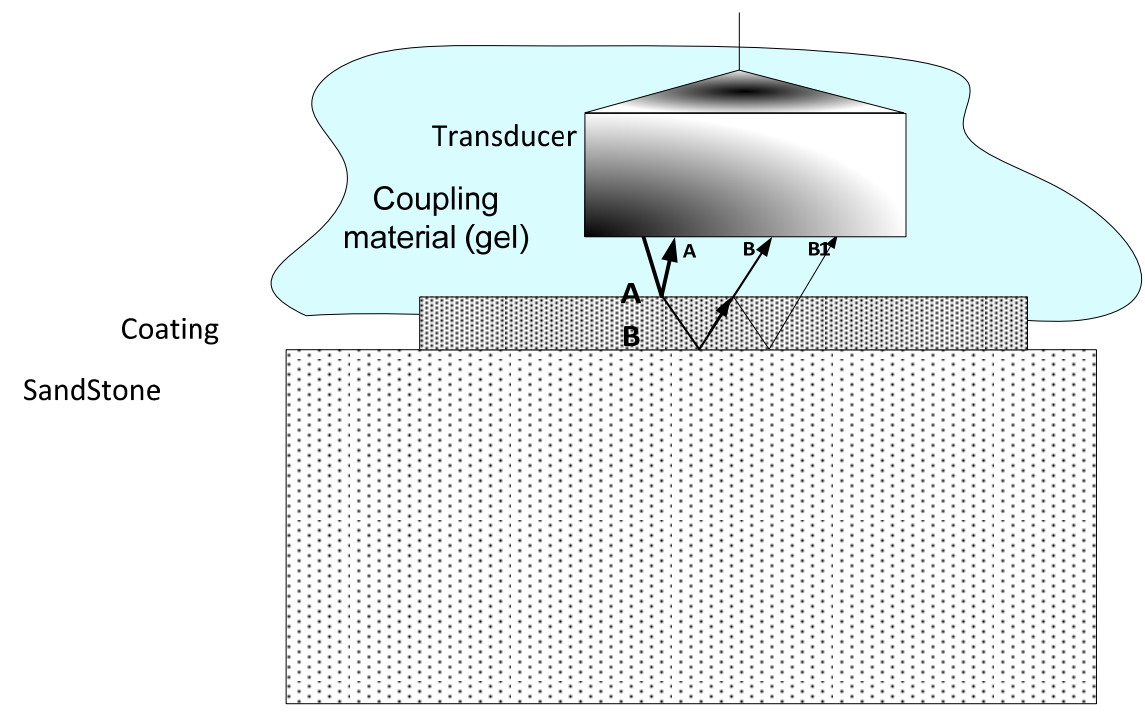

(a)

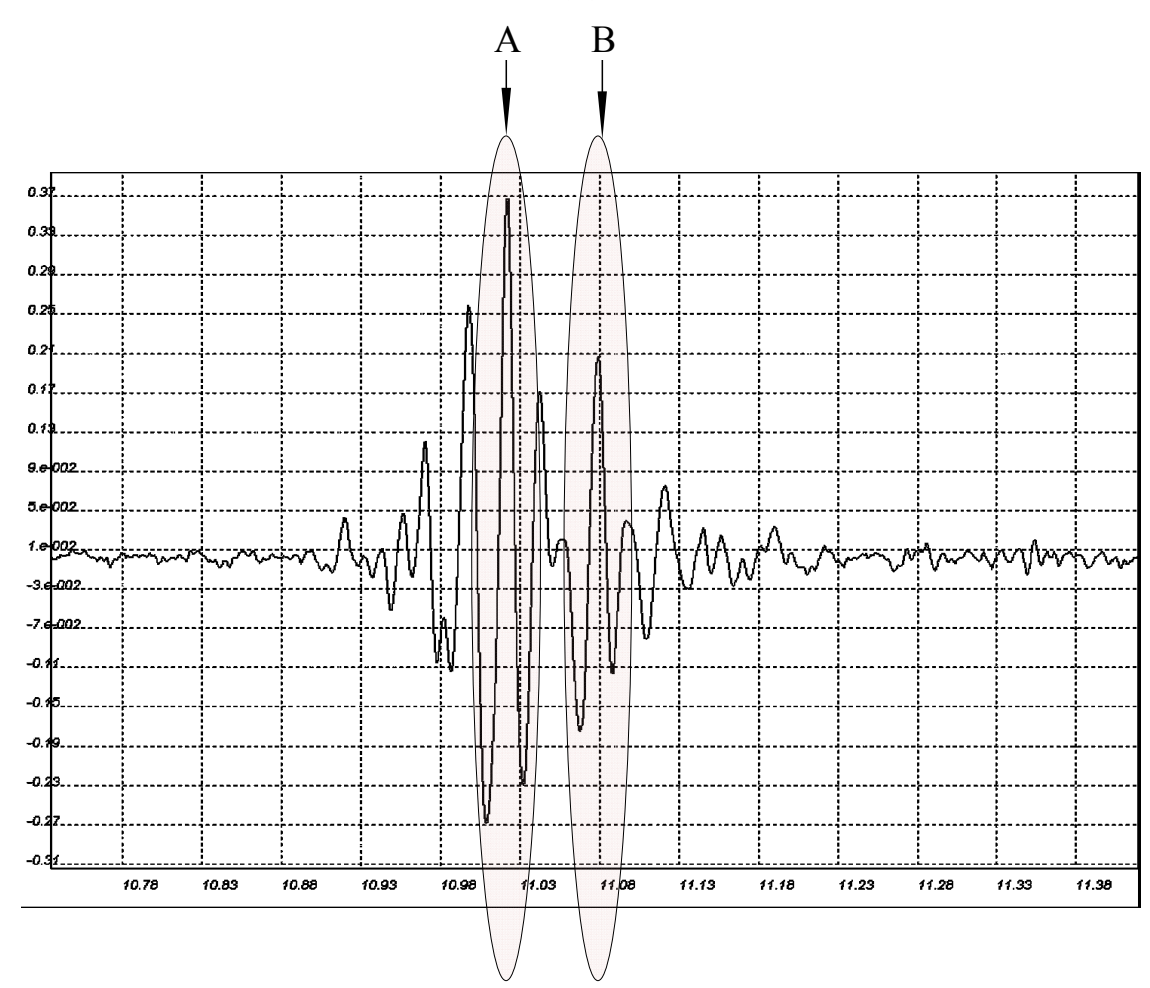

(b) 
The value of the propagation speed of the ultrasounds in the thin film material is required in order to determine the thickness of the thin film applied on the sandstone. For this reason, a reference layer of the thin film was created over a glass layer. The thickness of this reference film was $39 \mu \mathrm{m}$, measured using the Mitutoyo thickness micrometer with an accuracy of $1 \mu \mathrm{m}$ and uncertainty $3.25 \mu \mathrm{m}$, traceable and certified according to the ISO 17025 standard. Then, ten measurements of the ultrasonic waves' propagation time (time of flight-TOF) of this reference film were taken. The acoustic speed of the material is calculated as follows:

$$
c=\frac{2 \times s}{t}
$$

where $s$ is the thickness and $t$ corresponds to the time of flight (TOF) in the material. Using Equation (1), the acoustic speed of the thin film was calculated equal to $c=1609.89 \mathrm{~m} / \mathrm{s}$.

In order to evaluate the effectiveness of acoustic microscopy-based methodology in the estimation of the thin film thickness, five cases were measured, and for each thin film, ten measurements at different places were monitored. In each sandstone sample a gel layer is applied as a conductive layer between the transducer and the film surface. Each measurement is real time and thus very fast. In order to take measurements from different places we have only to move the transducer at these positions. The results are accumulated in Table 7. It seems that a layer of almost $30 \mu \mathrm{m}$ thickness was achieved when the hydrophobic solution was applied on the stone surface, while a finer layer was achieved when nanoparticles were added. The thickness varied from $16.5 \mu \mathrm{m}$ to $18.6 \mu \mathrm{m}$. The large uncertainty presented in measurements of the D6 sample is justified through the SEM observation of a cracked and not uniform layer.

Table 7. Measurement of the thin film thickness of the coatings, standard deviation and the mean value, based on the acoustic speed measured.

\begin{tabular}{cccc}
\hline Sample & Standard Deviation & Calculated Value $(\boldsymbol{\mu m}) *$ & Uncertainty \\
\hline D2 & 2.9796 & 30.4848 & 5.936 \\
D3 & 1.3459 & 17.1208 & 3.526 \\
D4 & 1.2322 & 18.5532 & 1.623 \\
D5 & 0.7833 & 18.6401 & 2.771 \\
D6 & 3.2555 & 16.5589 & 8.556 \\
\hline
\end{tabular}

Note: * Based on the measured thickness and the TOF between the echoes in the thin film (Mean Value).

\section{Results and Conclusions}

Samples from Demati sandstone were impregnated in a polymeric silicon solution enriched with nanosilica in different concentrations. The degree of the hydrophobicity succeeded was tested either through indirect ways, such as porosity and absorption tests, and also through direct measurements like water contact angle tests. From these tests it is derived that the treated samples present restricted water absorption and increased hydrophobicity as the static contact angle was $>140^{\circ}$ in many cases (in samples D3, D4, D5 and D6). The surface hydrophobicity of the sandstone has been almost tripled, ranging the static contact angle from $51.43^{\circ}$ for the untreated sample D1 to the maximum value of $143.73^{\circ}$ responding to sample D4 (1.5\% nanosilica), indicating a super-hydrophobic character. 
The sample treated with solution with $1.5 \%$ nanosilica present high solution absorption and the application of the layer was smooth and uniform. This can be attributed to the compatibility of the solution concentration with the porosity and the roughness of the substratum.

The thickness of the nano-modified coatings was recorded by the acoustic microscopy technique and it was $16.5-18.6 \mu \mathrm{m}$.

The microstructure analysis of the treated surfaces reveals the uniform and smooth application of the solutions with $1 \%$ and $1.5 \%$ nanosilica while a white layer of silica composition was formed on the stone surface in solutions rich in silica content (more than $2 \%$ ). The surface in these last cases was cracked and agglomeration phenomena took place. As a final and crucial point, freeze-thaw tests in air and saline solution environments present remarkable durability with lowest comparable material loss. This study proves the increased protection of the polymeric solutions modified with up to $1.5 \%$ nanosilica when applied on strong and dense stone surfaces like the Demati sandstones. In this way the stones used in decorative facades can present increased durability against water-introduced degradation.

\section{References}

1. European Standard EN 12440-2008 Natural Stone-Denomination Criteria; European Committee for Standardization: Brussels, Belgium, 2008.

2. Pope, G.A.; Meierding, T.C.; Paradise, T.R. Geomorphology's role in the study of weathering of cultural stone. Geomorphology 2002, 47, 211-225.

3. Fitzner, B.; Heinrichs, K. Kartierung und Bewertung von Verwitterungs-schäden an Natursteinbauwerken. Z. Ges. Geowiss. 2005, 156, 7-24.

4. Flügel, E. Microfacies of Carbonate Rocks: Analysis, Interpretation and Application, 2nd ed.; Springer: Berlin, Germany, 2010; pp. 895-902.

5. Myrin, M.; Malaga, K. Treatments on Gotland sandstone. In Fracture and Failure of Natural Building Stones: Applications in the Restoration of Ancient Monuments; Kourkoulis, S.K., Ed.; Springer: Berlin, Germany, 2006; pp. 577-590.

6. De Buergo Ballester, M.A.; Fort González, R. Basic methodology for the assessment and selection of water-repellent treatments applied on carbonatic materials. Prog. Org. Coat. 2001, $43,258-266$.

7. De Vries, J.; Polder, R.B. Building and Construction Research, Delft, The Netherlands Ing., Ministry of Transport, Civil Engineering Division, Utrecht, The Netherlands. Constr. Build. Mater, 1997, 11, 259-265.

8. Delgado, R.; Mimoso, M.J. Stone consolidation in cultural heritage, research and practice. In Proceedings of the International Symposium, Stone Consolidation in Cultural Heritage, Research and Practice, Lisbon, Portugal, 6-7 May 2008; pp. 193-201.

9. Vicini, S.; Mariani, A.; Princi, E.; Bidali, S.; Pincin, S.; Fiori, S. Frontal polymerization of acrylic monomers for the consolidation of stone. Polym. Adv. Technol. 2005, 16, 293-298.

10. Cardiano, P.; Ponterio, R.C.; Sergi, S.; Lo Schiavo, S.; Piraino, S. Epoxy-silica polymers as stone conservation materials. Polymer 2005, 46, 1857-1864.

11. Wheeler, G. Alkoxysilanes and the Consolidation of Stone; Getty Conservation Institute: Los Angeles, CA, USA, 2005. 
12. Constancio, C.; Franco, L.; Russo, A.; Anjinho, C.; Pires, J.; Fatima Vaz, M.; Ana, P.; Carvalho, J. Studies on polymeric conservation treatments of ceramic tiles with Poraloid B-72 and two alkoxysilanes. Appl. Polym. Sci. 2010, 116, 2833-2839.

13. Wu, Y.Y.; Sugimura, H.; Inoue, Y.; Takai, O. Thin films with nanotextures for transparent and ultra water-repellent coatings produced from trimethylmethoxysilane by microwave plasma CVD. Chem. Vap. Depos. 2002, 8, 47-50.

14. Matziaris, K.; Stefanidou, M.; Karagiannis, G. Impregnation and super-hydropho-bicity of coated porous low-fired clay building materials. Prog. Org. Coat. 2011, 72, 181-192.

15. Hansen, C. Water transport and condensation in fluoropolymer films. Prog. Org. Coat 2001, 42, 167-178.

16. Wacker Chemie AG Web Site. SILRES ${ }^{\circledR}$. Available online: http://www.wacker.com/cms/en/ products-markets/brands_3/silres/silres-home.jsp (accessed on 9 January 2013).

17. Shell Chemicals Web Site. Aliphatic Mineral Spirits Product Overview. Available online: http://www.shell.com/home/content/chemicals/products_services/our_products/solvents/hydrocar bon_solvents/aliphatic_mineral_spirits/product_overview/ (accessed on 9 January 2013).

18. Wacker Chemie AG Web Site. HDK ${ }^{\circledR}$ Pyrogenic Silica. Available online: http://www.wacker.com/ cms/en/products-markets/brands_2/hdk/hdk.jsp (accessed on 9 January 2013).

19. Recommandation, R. CPC 11.3. Absorption of water by immersion under vacuum. Mater. Struct. 1984, 17, 391-394.

20. Briggs, A. Advances in Acoustic Microscopy; Plenum Press: New York, NY, USA, 1995; Volume 1.

21. Briggs, A.; Arnold, W. Advances in Acoustic Microscopy; Plenum Press: New York, NY, USA, 1996; Volume 2.

22. Kolias, S. Investigation of the possibility of estimating concrete strength by porosity measurement. Mater. Struct. 1994, 27, 265-272.

23. ASTM D4404-10 Standard Test Method for Determination of Pore Volume and Pore Volume Distribution of Soil and Rock by Mercury Intrusion; ASTM International: West Conshohocken, PA, USA, 2010.

24. Stefanidou, M. Methods for porosity measurement in lime-based mortars. Constr. Build. Mater. 2010, 24, 2572-2578.

25. Ferreira, A.P.; Delgado Rodriguez, J. Assessment of Durability of Water Repellents by Means of Exposure Tests In Proceedings of the Ninth International Congress on Deterioration and Conservation of Stone, Venice, Italy, 19-24 June 2000; pp. 273-286.

26. Silva, Z.S.G.; Simão, J.A.R. The role of salt fog on alteration of dimension stone. Constr. Build. Mater. 2009, 23, 3321-3327.

27. EN12371:2001 Natural Stone Test Methods-Determination of Frost Resistance; European Committee for Standardization: Brussels, Belgium, 2001.

28. InfrArtSonic. Deliverable 3.2: Description of the simulation of the UV/VIS $/ \mathrm{nIR} / \mathrm{mIR}$ module operation. In Development of a Novel and Integrated Portable Non-Destructive Analysis System for the Documentation of Artworks; INCO-CT-2005-015338, Final Activity Report; InfrArtSonic: Ormylia, Greece, 2009. 
29. InfrArtSonic. Deliverable 4.x (4.1 and 4.2): Description of the Developed Prototype Infrartsonic System. In Development of a Novel and Integrated Portable Non-Destructive Analysis System for the Documentation of Artworks; INCO-CT-2005-015338, Final Activity Report; InfrArtSonic: Ormylia, Greece, 2009.

30. Karagiannis, G.; Alexiadis, D.; Sergiadis, G.; Salpistis, C. Processing of UV/VIS/nIR/mIR Diffuse Reflectance Spectra and Acoustic Microscopy Echo Graphs for Stratigraphy Determination, Using Neural Networks and Wavelet Transform. In Proceedings of 3rd International Conference on Information and Communication Technologies: From Theory to Applications 2008 (ICTTA 2008), Damascus, Syria, 7-11 April 2008.

(C) 2013 by the authors; licensee MDPI, Basel, Switzerland. This article is an open access article distributed under the terms and conditions of the Creative Commons Attribution license (http://creativecommons.org/licenses/by/3.0/). 